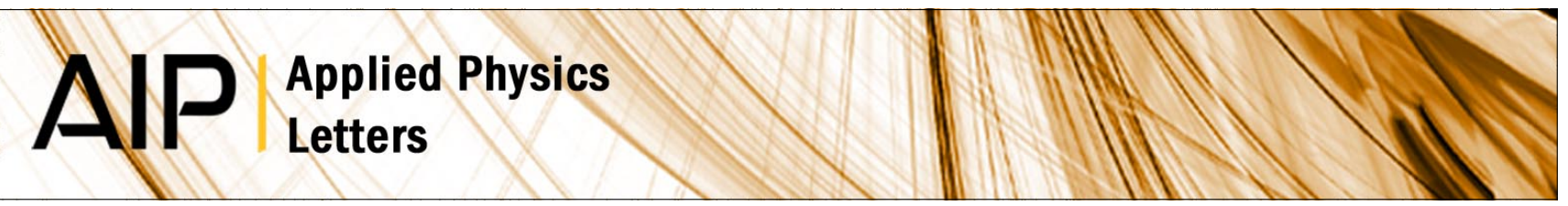

\title{
The critical growth velocity for planar-to-faceted interfaces transformation in SiGe crystals
}

Xinbo Yang, K. Fujiwara, N. V. Abrosimov, R. Gotoh, J. Nozawa et al.

Citation: Appl. Phys. Lett. 100, 141601 (2012); doi: 10.1063/1.3698336

View online: http://dx.doi.org/10.1063/1.3698336

View Table of Contents: http://apl.aip.org/resource/1/APPLAB/v100/i14

Published by the American Institute of Physics.

\section{Related Articles}

Disordered surface structure of an ultra-thin tin oxide film on $\mathrm{Rh}(100)$

J. Appl. Phys. 111, 064907 (2012)

Existence and removal of Cu2Se second phase in coevaporated Cu2ZnSnSe4 thin films

J. Appl. Phys. 111, 053522 (2012)

Control of the optical and crystalline properties of TiO2 in visible-light active TiO2/TiN bi-layer thin-film stacks

J. Appl. Phys. 111, 024301 (2012)

Surfactant enhanced solid phase epitaxy of $\mathrm{Ge} / \mathrm{CaF} 2 / \mathrm{Si}(111)$ : Synchrotron x-ray characterization of structure and morphology

J. Appl. Phys. 110, 102205 (2011)

Enhanced thermoelectric figure of merit in SiGe alloy nanowires by boundary and hole-phonon scattering J. Appl. Phys. 110, 074317 (2011)

\section{Additional information on Appl. Phys. Lett.}

Journal Homepage: http://apl.aip.org/

Journal Information: http://apl.aip.org/about/about_the_journal

Top downloads: http://apl.aip.org/features/most_downloaded

Information for Authors: http://apl.aip.org/authors

\section{ADVERTISEMENT}

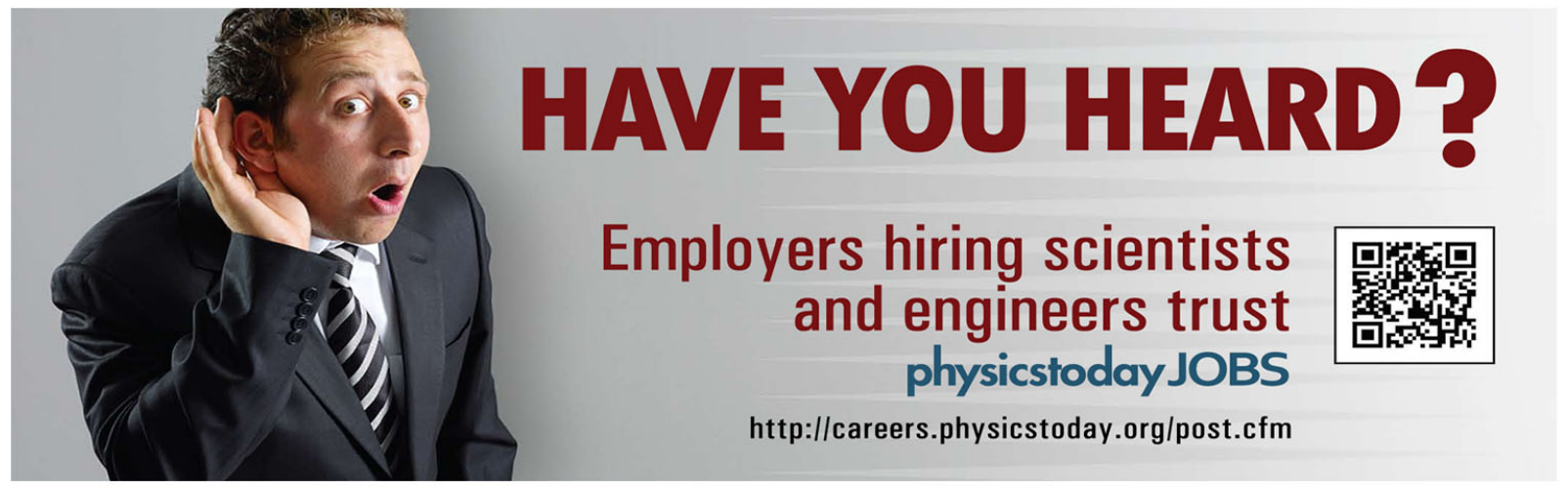




\title{
The critical growth velocity for planar-to-faceted interfaces transformation in SiGe crystals
}

\author{
Xinbo Yang,,${ }^{1,2, a)}$ K. Fujiwara, ${ }^{1}$ N. V. Abrosimov, ${ }^{3}$ R. Gotoh,,${ }^{1}$ J. Nozawa, ${ }^{1}$ H. Koizumi, ${ }^{1}$ \\ A. Kwasniewski, ${ }^{3}$ and $\mathrm{S}$. Uda ${ }^{1}$ \\ ${ }_{1}^{1}$ Institute for Materials Research (IMR), Tohoku University, Katahira 2-1-1, Aoba-ku, Sendai 980-8577, Japan \\ ${ }^{2}$ Research School of Engineering, College of Engineering and Computer Science, The Australian National \\ University, Canberra ACT 0200, Australia \\ ${ }^{3}$ Leibniz Institute for Crystal Growth (IKZ), Max-Born-St. 2, 12489 Berlin, Germany
}

(Received 1 January 2012; accepted 12 March 2012; published online 2 April 2012)

\begin{abstract}
Crystal-melt interface morphological transformation of differently oriented SiGe crystals with different Ge concentrations was observed, and the effect of Ge concentration on critical growth velocity $\left(V_{\mathrm{c}}\right)$ for the interface morphological transformation was investigated. A planar-to-faceted morphological transformation for the $\langle 110\rangle,\langle 112\rangle$, and $\langle 100\rangle$ interfaces was observed. $V_{\mathrm{c}}$ for planar-to-faceted transformation of the $\langle 110\rangle,\langle 112\rangle$, and $\langle 100\rangle$ interfaces decreases nonlinearly with increasing Ge concentration. SiGe faceted interfaces can be attributed to the fact that the perturbation induced in a planar interface was amplified when the constitutional undercooled zone was formed at high growth velocities. (C) 2012 American Institute of Physics. [http://dx.doi.org/10.1063/1.3698336]
\end{abstract}

Silicon-germanium crystals $\left(\mathrm{Si}_{1-\mathrm{x}} \mathrm{Ge}_{\mathrm{x}}\right.$, shorted as $\left.\mathrm{SiGe}\right)$, which are promising materials for advanced electronic and optoelectronic devices, have attracted considerable interest recently. ${ }^{1-3}$ At present, however, SiGe crystals are used mainly in the form of $\mathrm{Si} / \mathrm{SiGe}$ heterostructures and epilayers, ${ }^{4-7}$ because the growth of high-quality SiGe bulk crystals is very difficult owing to the strong segregation of the components during crystal growth, which leads to constitutional undercooling in the melt near the front of crystallization. ${ }^{8}$ Many techniques, such as Czochralski $(\mathrm{Cz})$, horizontal and vertical Bridgman, electron-beam, and float zone methods, have been developed to grow bulk SiGe crystals, and usually a low growth velocity is necessary for stable growth to avoid constitutional undercooling. ${ }^{3,9,10}$ However, the successful growth of SiGe crystals with high performance remains difficult, especially with increasing germanium concentration.

In the growth of crystals from a melt, the properties of crystal-melt interfaces often play a critical role in controlling macro- and micro-structures and defect density. The main difficulty in growing high-quality SiGe crystals is due to the strong segregation of components during the growth, ${ }^{8}$ which depends partly on the shape of the crystal-melt interface during growth. Therefore, controlling the crystal-melt interface morphology during the crystal growth is crucial to obtaining high-quality SiGe crystals. Faceting is a fundamental concern in crystal growth, and the faceted solid-liquid interface of silicon has been frequently investigated. ${ }^{11-13}$ Faceting is also observed during the epitaxial growth of SiGe films, ${ }^{14,15}$ and cellular structure evolution during the growth of $\mathrm{Ge}_{1-\mathrm{x}} \mathrm{Si}_{\mathrm{x}}$ single crystals has been investigated by simulations. ${ }^{16,17}$ Recently, we have reported the $\langle 100\rangle$ crystal-melt interface morphological transformation from a planar to a zigzag facets to a faceted cellular in $\mathrm{Si}_{0.85} \mathrm{Ge}_{0.15}$ crystal and formation mechanism of the cellular structure was clarified. ${ }^{18}$ However, the effect of $\mathrm{Ge}$ concentration on the crystal-melt interface

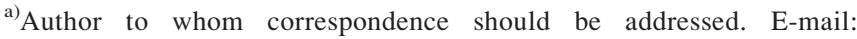
xinbo.yang@anu.edu.au or louis.xbyang@gmail.com. Tel.: +61 (0)2 61970112.
}

morphological transformation in SiGe crystal is still unknown. In this work, a panar-to-faceted transformation of crystal-melt interfaces of differently oriented SiGe crystals with different Ge concentrations was observed using in situ observation, and the effect of Ge concentration on critical growth velocity for interface morphological transformation was investigated.

An in situ observation system consisting of a furnace and a microscope ${ }^{12,13}$ was used for observing the crystalmelt interfaces of SiGe crystals. High-quality SiGe crystals with different $\mathrm{Ge}$ concentrations ( 1 at. $\%, 3$ at. $\%, 5$ at. $\%$, and 7 at. \%) grown by the $\mathrm{Cz}$ method in IKZ (Refs. 8 and 9) were used this time, instead of the sample formed by melting Ge and Si wafers. ${ }^{18}$ The experimental procedure is shown in Fig. 1 . SiGe sheets $\left(20 \times 10 \times 1 \mathrm{~mm}^{3}\right)$ with the required orientations were dipped in a buffered hydrofluoric acid (HF) solution for $2 \mathrm{~min}$ to remove the oxide layer from the surface before setting them in a quartz crucible. After pumping to a low vacuum, the furnace was filled with high-purity argon gas and then heated. The sample was melted in such a way that an unmelted portion remained, which served as the seed crystal. Then, the furnace was cooled at different rates. Generally, crystal growth began at the initial crystal-melt interface along the side orientation with different growth velocities. Images of the samples during melting and crystallization were monitored and recorded on videotape.

Figure 2 shows the $\langle 110\rangle$-oriented crystal-melt interfaces of $\mathrm{Si}_{0.99} \mathrm{Ge}_{0.01}(1$ at. \% Ge) with different growth velocities. After cooling, the crystal growth began at the interface. The interface was planar when the growth velocity was $49 \mu \mathrm{m} / \mathrm{s}$ [Fig. 2(a)], and the planar interface was maintained throughout the crystal growth. At lower growth velocities, a planar $\langle 110\rangle$ interface was always observed. When the interface growth velocity was increased to $55 \mu \mathrm{m} / \mathrm{s}$, an interface morphological transformation from planar to zigzag facets was observed [Fig. 2(b)], which can also be observed at higher growth velocities. A similar interface morphological transformation from planar to zigzag facets was also observed in silicon crystals of different orientations. ${ }^{12,13}$ For 


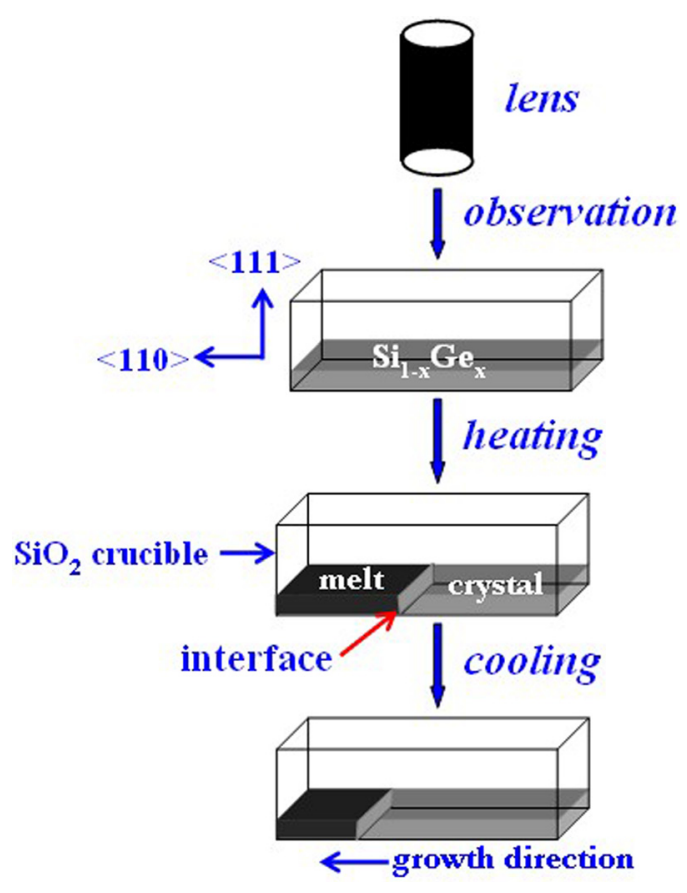

FIG. 1. Experimental procedure for in situ observation of crystal-melt interfaces of differently oriented SiGe crystals.

the $\langle 110\rangle$-oriented silicon interface, this morphology transformation occurred when the interface growth velocity was $124 \mu \mathrm{m} / \mathrm{s}$ or higher, ${ }^{13}$ which is more than two times higher than that required for the $\mathrm{Si}_{0.99} \mathrm{Ge}_{0.01}$ crystal. The result indicates that the interface growth velocity for the planar-to-facets transformation of silicon decreases quickly as the doping of germanium.

Similar experiments were carried out using $\mathrm{SiGe}$ crystals with different $\mathrm{Ge}$ concentrations. A planar interface was observed in the $\mathrm{Si}_{0.97} \mathrm{Ge}_{0.03}$ ( 3 at. \% Ge) crystal when the interface growth velocity was $32 \mu \mathrm{m} / \mathrm{s}$ or lower, whereas the interface transformed from planar to zigzag facets when the interface growth velocity was slightly increased to $36 \mu \mathrm{m} / \mathrm{s}$.
When the Ge concentration in SiGe sample was increased to 5 at. \%, the crystal-melt interface was planar when the growth velocity was $21 \mu \mathrm{m} / \mathrm{s}$ or lower, and the interface transformation from planar to facets occurred at a growth velocity of $23 \mu \mathrm{m} / \mathrm{s}$ or higher. Figure 3(a) shows the melt process of the $\mathrm{Si}_{0.93} \mathrm{Ge}_{0.07}$ (7 at. \% Ge) crystal, in which a blurry layer ( $\sim 2 \mathrm{~mm}$ width) was observed in front of the crystal-melt interface. The layer was identified as a polycrystalline wetting layer on the crystal surface, ${ }^{19}$ which was not observed for SiGe crystals with lower Ge concentrations as well as in our previous work. ${ }^{18}$ We observed that the transformation from planar to facets of the interface occurred when the interface growth velocity was between 12 and $13 \mu \mathrm{m} / \mathrm{s}$ [Fig. 3(b)]. Here, we define the critical growth velocity $\left(V_{\mathrm{c}}\right)$ for the interface morphological transformation as the average of two experimental values. For example, for the $\mathrm{Si}_{0.95} \mathrm{Ge}_{0.05}$ sample, $V_{\mathrm{c}}$ is calculated as the average of 21 and $23 \mu \mathrm{m} / \mathrm{s}$, i.e., $22 \mu \mathrm{m} / \mathrm{s}$. Therefore, the experimental results indicate that $V_{\mathrm{c}}$ for the $\langle 110\rangle$-oriented interface morphological transformation from planar to facets decreases with increasing $\mathrm{Ge}$ concentration.

The $\langle 112\rangle$ and $\langle 100\rangle$ interface morphological transformations in SiGe crystals with different Ge concentrations were also investigated by the same experimental procedure. We observed that the $\langle 112\rangle$ and $\langle 100\rangle$ interfaces also exhibited a planar-to-faceted morphological transformation with increasing interface growth velocity. The obtained experimental growth velocities for the $\langle 110\rangle,\langle 112\rangle$, and $\langle 100\rangle$ interface morphological transformations of SiGe crystals with different Ge concentrations are summarized in Table I, and the $V_{\mathrm{c}}$ values calculated are shown in brackets. No data of the $\langle 112\rangle$ oriented $\mathrm{Si}_{0.93} \mathrm{Ge}_{0.07}(7$ at. \% Ge) crystal are available because of the short of sample. Figure 4 shows the $V_{\mathrm{c}}$ values of the differently oriented interfaces as functions of Ge concentration in SiGe crystals, and the $V_{\mathrm{c}}$ of pure silicon ${ }^{12}$ was shown together. For all the $\langle 110\rangle,\langle 112\rangle$, and $\langle 100\rangle$ interfaces, $V_{\mathrm{c}}$ for planar-to-faceted interface transformation decreases nonlinearly with increasing Ge concentration. For a SiGe crystal with a certain $\mathrm{Ge}$ concentration, the $V_{\mathrm{c}}$ values show small (a)

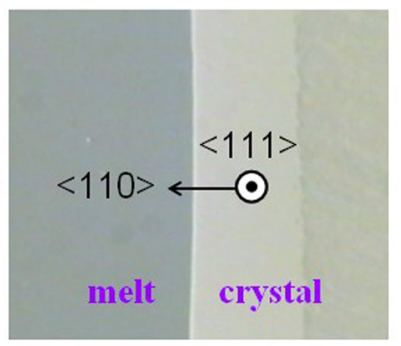

$$
\mathbf{t}=\mathbf{0} \mathrm{s}
$$

(b)

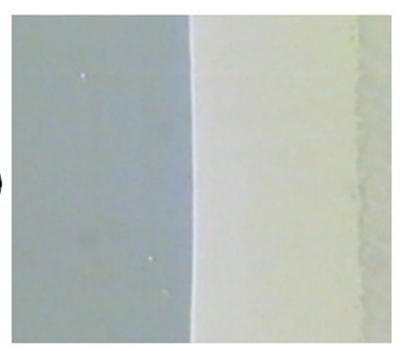

$\mathbf{t}=\mathbf{0} \mathrm{s}$

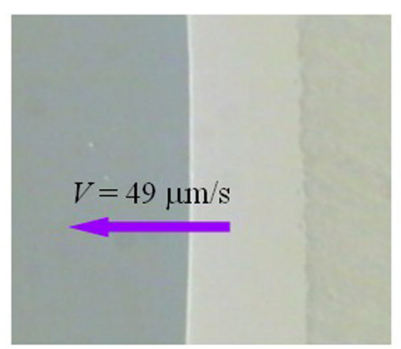

$\mathbf{t}=1.0 \mathrm{~s}$

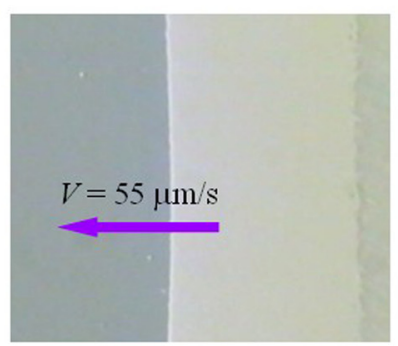

$\mathbf{t}=\mathbf{1 . 5} \mathrm{s}$

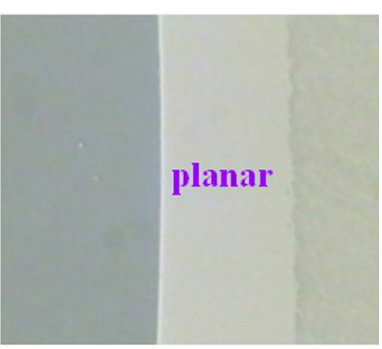

$\mathbf{t}=\mathbf{3 . 0} \mathrm{s}$

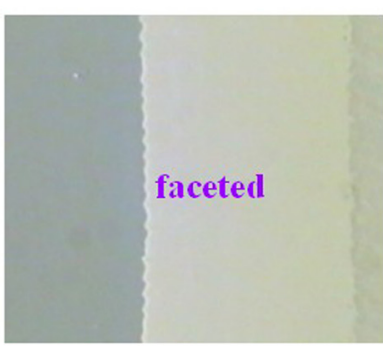

$\mathbf{t}=\mathbf{3 . 0} \mathrm{s}$
FIG. 2. Crystal-melt interface of the $\mathrm{Si}_{0.99} \mathrm{Ge}_{0.01}$ crystal grown in $\langle 110\rangle$ orientation at different velocities: (a) $49 \mu \mathrm{m} / \mathrm{s}$, planar interface and (b) $55 \mu \mathrm{m} / \mathrm{s}$, planarto-faceted interface. 


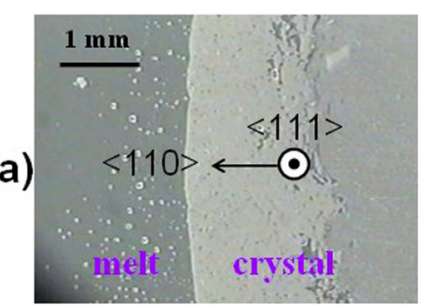

$\mathbf{t}=\mathbf{0} \mathrm{s}$

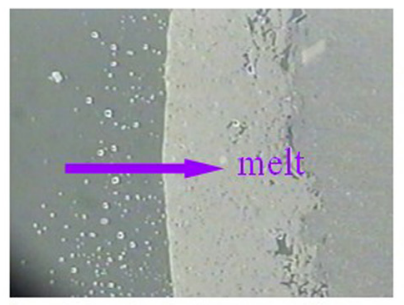

$\mathbf{t}=\mathbf{3 . 0} \mathrm{s}$

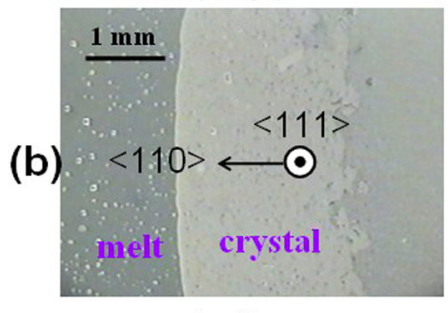

$\mathbf{t}=\mathbf{0} \mathrm{s}$

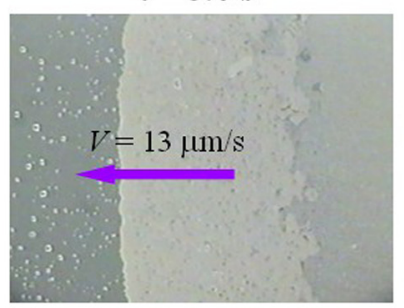

$\mathbf{t}=\mathbf{5 . 0} \mathrm{s}$

difference for interfaces of different orientations, which may attribute to the different interfacial energy of different orientations. The results indicate that $V_{\mathrm{c}}$ is mainly determined by the Ge concentration and is weakly dependent of interface orientation.

Fujiwara et al. reported that wavy perturbation is induced in a planar crystal-melt interface of silicon, and the perturbation was amplified and resulted in zigzag facets. Faceted interfaces were formed at high growth velocities because the perturbation induced in a planar interface was amplified when the temperature gradient became negative owing to the latent heat of crystallization. ${ }^{12}$ The effect of constitutional undercooling was neglected for their work because the sample is high-purity silicon. For SiGe crystals, however, this is not the case. During the SiGe crystals growth, there is a substantial change in the concentration ahead of the interface. Depending on the temperature gradient in the liquid at the crystal-melt interface, there may exist a zone of constitutional undercooling, in which the actual temperature is lower than the local equilibrium solidification temperature. According to the constitutional undercooling theory, ${ }^{20,21}$ this undercooling results in the instability of the planar interface since any perturbation forming on the interface would find itself in undercooled liquid and, therefore, would be amplified and form facets. The constitutional undercooling criterion was developed quantitatively by considering heat and mass flow only at the interface, that is, a planar interface is stable when, ${ }^{21}$

TABLE I. Experimental growth velocities for $\langle 110\rangle,\langle 112\rangle$, and $\langle 100\rangle$ interface transformations from planar to facets of $\mathrm{SiGe}$ crystals with different $\mathrm{Ge}$ concentrations, $V_{\mathrm{c}}$ values are shown in brackets.

\begin{tabular}{lccc}
\hline \hline Ge (at. \%) & $\langle 110\rangle-V_{\mathrm{c}}(\mu \mathrm{m} / \mathrm{s})$ & $\langle 112\rangle-V_{\mathrm{c}}(\mu \mathrm{m} / \mathrm{s})$ & $\langle 100\rangle-V_{\mathrm{c}}(\mu \mathrm{m} / \mathrm{s})$ \\
\hline $0^{\mathrm{a}}$ & $107 \sim 124(115.5)$ & $102 \sim 129(115.5)$ & $123 \sim 147(135)$ \\
1 & $49 \sim 55(52)$ & $44 \sim 52(48)$ & $52 \sim 64(58)$ \\
3 & $32 \sim 36(34)$ & $25 \sim 29(27)$ & $27 \sim 34(30.5)$ \\
5 & $21 \sim 23(22)$ & $22 \sim 24(23)$ & $23 \sim 27(25)$ \\
7 & $12 \sim 13(12.5)$ & - & $14 \sim 16(15)$ \\
\hline \hline
\end{tabular}

${ }^{\mathrm{a}}$ Experimental data cited from Ref. 13.

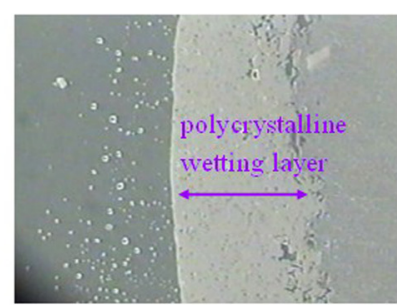

$\mathbf{t}=7.0 \mathrm{~s}$

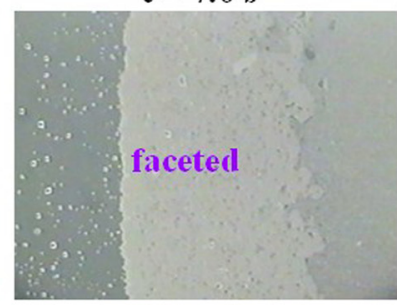

$\mathrm{t}=\mathbf{8 . 0 \mathrm { s }}$
FIG. 3. Crystal-melt interface of the $\mathrm{Si}_{0.93} \mathrm{Ge}_{0.07}$ crystal in $\langle 110\rangle$ orientation (a) melt process and (b) interface grow velocity of $13 \mu \mathrm{m} / \mathrm{s}$, planar-to-faceted interface.

$$
\frac{G_{L}}{V} \geq \frac{m_{L} C_{0}(1-k)}{D_{L}}
$$

where $G_{L}$ is the actual temperature gradient in the liquid at the interface, $V$ is the interface growth velocity, $m_{L}$ is the slope of the liquidus line in the phase diagram, $C_{0}$ is the initial solute concentration in the liquid, $D_{L}$ is the diffusion coefficient of the solute (Ge in our case), and $k$ is the segregation coefficient. According to Eq. (1), a planar interface becomes unstable as the interface growth velocity increases. For the in situ observation of the crystal-melt interface of SiGe crystal, $G_{L}, m_{L}, D_{L}$, and $k$ can be considered as constants. Therefore, the relationship between $V_{\mathrm{c}}$ and the Ge concentration $C_{0}$ can be written as,

$$
V_{c}=\frac{G_{L}}{K_{0}} C_{0}^{-1}
$$

Where $K_{0}=\frac{D_{L}}{m_{L}(1-k)}$. Equation (2) indicates that $V_{\mathrm{c}}$ decreases with increasing Ge concentration, which is consistent with our experimental results as shown in Fig. 4. We used Eq. (2)

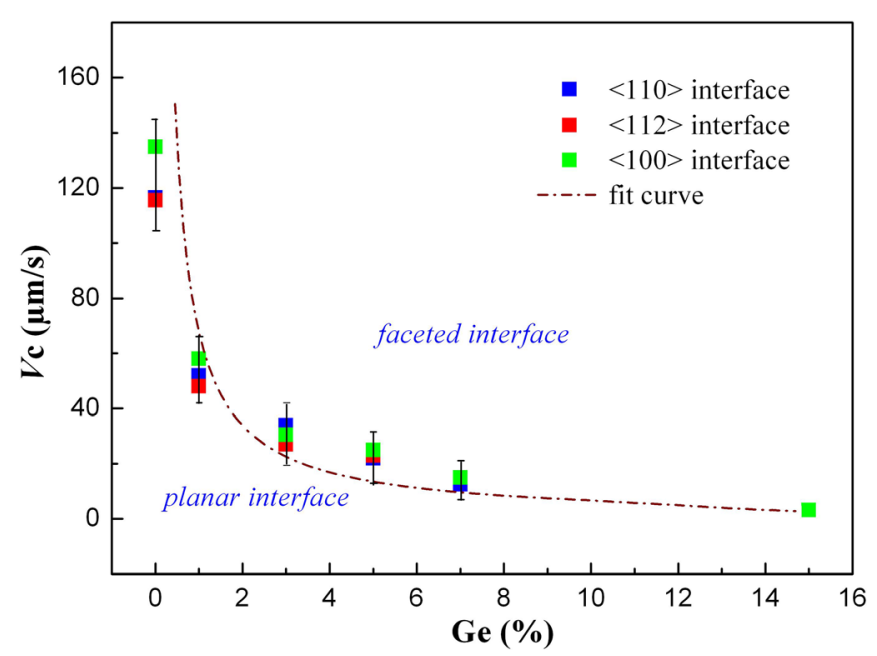

FIG. 4. $V_{\mathrm{c}}$ values for morphological transformation of differently oriented interfaces as functions of Ge concentration in SiGe crystals. 
to fit the experimental results, as shown by the brown dash-dotted line in Fig. 4. Equation (2) fits well with the experimental results in a low interface growth velocity region. However, a large fit error was observed for the result of pure silicon. As reported by Tokairin et al., ${ }^{12}$ the $\mathrm{G}_{\mathrm{L}}$, which was decided by the thermal undercooling, should be negative for the faceted interface to develop in pure silicon and is not constant. Equation (2) only works well when the initial solute concentrations $\mathrm{C}_{0}$ is large enough, and the thermal undercooling does not exist. ${ }^{21}$ The fitting results of $G_{L}$ and $K_{0}$ in the high $\mathrm{C}_{0}$ region $(>0.5$ at. $\% \mathrm{Ge})$ are $85 \mathrm{~K} / \mathrm{cm}$ and 1.55 , respectively. $G_{L}$ is very close to the measured temperature gradient of the in situ observation furnace $(\sim 80 \mathrm{~K} / \mathrm{cm})$. We have reported that the $V_{\mathrm{c}}$ of $\mathrm{Si}_{0.85} \mathrm{Ge}_{0.15}$ crystal was between 1 and $5.8 \mu \mathrm{m} / \mathrm{s},{ }^{18}$ which agrees well with the fitting value $(\sim 3.2 \mu \mathrm{m} /$ s) as shown in Fig. 4. Therefore, we concluded that the faceted interfaces of SiGe crystals were formed at high growth velocities because the perturbation introduced into a planar interface was amplified when the constitutional undercooled zone formed near the interfaces.

In summary, we have investigated the $\langle 110\rangle,\langle 112\rangle$, and $\langle 100\rangle$ interface morphological transformation of SiGe crystals with different Ge concentrations. With increasing interface growth velocity, a planar-to-faceted morphological transformation was observed for the $\langle 110\rangle,\langle 112\rangle$, and $\langle 100\rangle$ interfaces. $V_{\mathrm{c}}$ for the interface morphological transformation, which was mainly determined by Ge concentration and is almost independent of interface orientation, decreases nonlinearly with increasing Ge concentration. The constitutional undercooling criterion equation fits well with the experimental results, which indicates that the $V_{\mathrm{c}}$ of the SiGe crystals with high $\mathrm{Ge}$ concentrations can be predicted using the equation. When the interface growth velocity reaches $V_{\mathrm{c}}$, a constitutional undercooling zone forms near the interface, and the perturbation induced in a planar interface is amplified, and resulting in the facets.
Xinbo Yang gratefully acknowledges the Japan Society for the Promotion of Science (JSPS) Postdoctoral Fellowship for financial support. This work was partially funded by the Cabinet Office, Government of Japan through its "Funding Program for Next Generation World-Leading Researchers."

${ }^{1}$ N. V. Abrosimov, A. Ludge, H. Riemann, and W. Schroder, J. Cryst. Growth 237-239, 356 (2002).

${ }^{2}$ I. Yonenaga, J. Cryst. Growth 275, 91 (2005).

${ }^{3}$ K. Fujiwara, W. Pan, N. Usami, K. Sawada, A. Nomura, T. Ujihara, T. Shishido, and K. Nakajima, J. Cryst. Growth 275, 467 (2005).

${ }^{4}$ M. Hanke, M. Schmidbauer, R. Kohler, F. Syrowatka, A. K. Gerlitzke, and T. Boeck, Appl. Phys. Lett. 84, 5228 (2004).

${ }^{5}$ M. Hanke, T. Boeck, A. K. Gerlitzke, F. Syrowatka, and F. Heyroth, Appl. Phys. Lett. 86, 223109 (2005).

${ }^{6} \mathrm{~T}$. Teubner and T. Boeck, J. Cryst. Growth 289, 366 (2006).

${ }^{7}$ M. Itakura, S. Masumori, N. Kuwano, H. Kanno, T. Sadoh, and M. Miyao, Appl. Phys. Lett. 96, 182101 (2010).

${ }^{8}$ N. V. Abrosimov, S. N. Rossolenko, W. Thieme, A. Gerhardt, and W. Schroder, J. Cryst. Growth 174, 182 (1997).

${ }^{9}$ N. V. Abrosimov, S. N. Rossolenko, V. Alex, A. Gerhardt, and W. Schroder, J. Cryst. Growth 166, 657 (1996).

${ }^{10}$ N. Usami, M. Kitamura, K. Obara, Y. Nose, T. Shishido, and K. Nakajima, J. Cryst. Growth 284, 57 (2005).

${ }^{11}$ U. Landman, W. D. Luedtke, R. N. Barnett, C. L. Cleveland, M. W. Ribarsky, E. Arnold, S. Ramesh, H. Baumgart, A. Martinez, and B. Khan, Phys. Rev. Lett. 56, 155 (1986).

${ }^{12}$ M. Tokairin, K. Fujiwara, K. Kutsukake, N. Usami, and K. Nakajima, Phys. Rev. B 80, 174108 (2009).

${ }^{13}$ K. Fujiwara, R. Gotoh, X. B. Yang, H. Koizumi, J. Nozawa, and S. Uda, Acta Mater. 59, 4700 (2011).

${ }^{14}$ M. A. Lutz, R. M. Feenstra, P. M. Mooney, J. Tersoff, and J. O. Chu, Surf. Sci. Lett. 316, L1075 (1994).

${ }^{15}$ C. Pribat, G. Servanton, L. Depoyan, and D. Dutartre, Solid-State Electron. 53, 865 (2009).

${ }^{16}$ W. Miller, N. Abrosimov, I. Rasin, and D. Borissova, J. Cryst. Growth 310, 1405 (2008).

${ }^{17}$ W. Miller, I. Rasin, and D. Stock, Phys. Rev. E 81, 051604 (2010).

${ }^{18}$ R. Gotoh, K. Fujiwara, X. B. Yang, H. Koizumi, J. Nozawa, and S. Uda, Appl. Phys. Lett. 100, 021903 (2012).

${ }^{19}$ M. Kurten and J. Schilz, J. Cryst. Growth 141, 473 (1994).

${ }^{20}$ J. W. Rutter and B. Chalmers, Can. J. Phys. 31, 15 (1953).

${ }^{21}$ W. A. Tiller, K. A. Jackson, J. W. Rutter, and B. Chalmers, Acta Metall. 1, 428 (1953). 